\title{
Chronic hypoxemia increases myocardial cytochrome oxidase
}

\author{
David A. Piel, BS, ${ }^{\text {a* }}$ Azeem R. Khan, MD, ${ }^{\text {b* }}$ Robert Waibel, BS, ${ }^{\mathrm{b}}$ Mariusz Birbach, MD, ${ }^{\mathrm{b}}$ Meryl S. Cohen, MD, \\ Thomas L. Spray, MD, ${ }^{b}$ Clifford S. Deutschman, MD, ${ }^{d}$ J. William Gaynor, MD, ${ }^{b}$ and Richard J. Levy, MDa
}

From the Department of Anesthesiology and Critical Care Medicine, ${ }^{a}$ the Division of Cardiothoracic Surgery, Department of Surgery, ${ }^{\mathrm{b}}$ and the Division of Cardiology, Department of Pediatrics, ${ }^{\mathrm{c}}$ Children's Hospital of Philadelphia, University of Pennsylvania, and the Department of Anesthesia, ${ }^{\mathrm{d}}$ University of Pennsylvania School of Medicine, Philadelphia, Pa.

Supported by the Alice Langdon Warner and Daniel M. Tabas Endowed Chairs in Pediatric Cardiothoracic Surgery at The Children's Hospital of Philadelphia.

Received for publication Nov 2, 2004; revisions received May 25, 2005; accepted for publication June 7, 2005.

Address for reprints: Richard J. Levy, MD, Department of Anesthesiology and Critical Care Medicine, 9th Floor, Children's Hospital of Philadelphia, 34th St and Civic Center Blvd, Philadelphia, PA 19106 (Email: levyri@email.chop.edu).

*Both Mr Piel and Dr Khan contributed equally to this study.

J Thorac Cardiovasc Surg 2005;130:1101-6

$0022-5223 / \$ 30.00$

Copyright $\odot 2005$ by The American Association for Thoracic Surgery

doi:10.1016/j.jtcvs.2005.06.030
Objective: Cyanotic patients have potentially decreased tissue oxygen tension. Cytochrome oxidase catalyzes the reduction of oxygen and is integral to adenosine triphosphate production. Cytochrome oxidase subunit I, the active site, is encoded by mitochondrial DNA. Using a newborn swine model of chronic hypoxemia, we evaluated ventricular cytochrome oxidase subunit I mRNA and protein expression and assessed cytochrome oxidase activity.

Methods: Thirty-two newborn piglets underwent thoracotomy and placement of a pulmonary artery-to-left atrium shunt or sham operation. Two weeks later, partial pressure of arterial oxygen, hematocrit, and left ventricular shortening fraction values were compared with baseline values. Northern blot hybridization and protein immunoblotting for ventricular cytochrome oxidase subunit I were performed. Cytochrome oxidase kinetic activity was measured. Heme a, $\mathrm{a}_{3}$ content and turnover number were determined. Significance was assessed with a $t$ test.

Results: Baseline partial pressure of arterial oxygen and hematocrit values were similar. Hypoxemic piglets had a lower partial pressure of arterial oxygen of $38 \pm$ $10 \mathrm{~mm} \mathrm{Hg}(P<.001)$ and higher hematocrit value of $31.4 \% \pm 2.9 \%(P<.001)$ compared with a partial pressure of arterial oxygen of $140 \pm 47 \mathrm{~mm} \mathrm{Hg}$ and hematocrit value of $24.6 \% \pm 3.9 \%$ after the sham operation. Baseline and postprocedure left ventricular shortening fraction were similar within and between groups. Chronic hypoxemia increased right ventricular and left ventricular cytochrome oxidase I mRNA and protein by more than 1.4-fold. Cytochrome oxidase activity increased significantly in hypoxemia by 2.5 -fold compared with that seen after the sham operation. Heme $\mathrm{a}, \mathrm{a}_{3}$ content and turnover number increased by 1.5 -fold during hypoxemia.

Conclusions: Chronic hypoxemia increases cytochrome oxidase I message, protein expression, and activity. The increase in kinetics was due to increased enzyme content and catalytic activity. This is a possible adaptive mechanism that might preserve organ function during chronic hypoxemia.

$\mathrm{C}$ hildren with congenital cyanotic heart disease have higher perioperative morbidity and mortality compared with acyanotic patients. ${ }^{1}$ Prolonged inotropic and ventilatory support and longer duration of intensive care unit stay are often seen in patients with higher degrees of preoperative cyanosis. ${ }^{2}$

The cyanotic heart has been shown to be less tolerant to global ischemia, demonstrating abnormalities with both systolic and diastolic function. ${ }^{3}$ On reperfusion, cyanotic hearts have relatively lower heart rates, decreased developed left ventricular pressure and ejection fraction, and increased left ventricular end-diastolic pressure. ${ }^{3}$ Furthermore, bioenergy availability is altered after ischemia. ${ }^{2}$ Myocardial adenosine triphosphate (ATP) levels are significantly decreased in cyanotic hearts on reperfusion compared with levels in acyanotic control hearts. ${ }^{1,2}$ 
Before ischemia and preoperatively, however, cyanotic hearts exhibit no difference in cardiac performance or ATP content. $^{2-4}$

Many have hypothesized that chronic hypoxia associated with cyanotic heart disease induces cellular adaptive mechanisms to preserve organ function and minimize hypoxic injury. ${ }^{5}$ One possible mechanism could be upregulation of the enzymes involved in ATP synthesis through oxidative phosphorylation. ${ }^{6}$ Complex IV of the electron transport chain, located on the inner membrane of the mitochondrion, is cytochrome c oxidase $(\mathrm{CcOx})$. CcOx, the terminal oxidase of the chain, catalyzes the reduction of oxygen to water by using electrons from reduced cytochrome $\mathrm{c}$ generated by complex III. The consumption of oxygen in this process is closely linked to proton pumping across the inner mitochondrial membrane. Complex V uses the transmembrane proton gradient created by complexes I, III, and IV for ATP generation. In cyanotic heart disease chronic hypoxia can potentially result in relatively decreased tissue oxygen tension. Because the site of oxygen reduction is complex IV, in the setting of chronic hypoxemia, the mitochondrial enzyme complex most intriguing to study is $\mathrm{CcOx}$.

CcOx is made up of 13 subunits. Ten structural subunits are encoded by nuclear DNA, whereas subunits I to III, which make up the catalytic center of the enzyme, are encoded by mitochondrial DNA. CcOx subunit I contains the heme $\mathrm{a}_{3} \mathrm{a}_{3}$ binuclear center and is the active site of the enzyme. Using a newborn porcine model of chronic hypoxia, we hypothesized that one adaptive cellular mechanism during cyanosis is increased myocardial $\mathrm{CcOx}$ expression and activity. We specifically evaluated one of the most important $\mathrm{CcOx}$ subunits, subunit I, the active site.

\section{Materials and Methods Animal Model}

Experiments were approved by the Institutional Animal Care and Use Committee of The Children's Hospital of Philadelphia, and all animals received humane care in compliance with the guidelines of the National Institute of Health.

Thirty-two 7- to 10-day-old neonatal piglets $(2.6-3.8 \mathrm{~kg})$ were randomized to either creation of a left pulmonary artery-to-left atrium shunt (hypoxemic group, $\mathrm{n}=16$ ) or sham operation $(\mathrm{n}=16){ }^{7}$ After administration of intramuscular ketamine $(30 \mathrm{mg} / \mathrm{kg}$ ), acepromazine $(1.2 \mathrm{mg} / \mathrm{kg})$, and buprenorphine hydrochloride $(0.1 \mathrm{mg} / \mathrm{kg})$, animals were endotracheally intubated. After achievement of general anesthesia with isoflurane $(1.5 \%)$ piglets were positioned in the left lateral decubitus position. Baseline left ventricular shortening fraction (SF) was measured by using short-axis 2-dimensional and M-mode transthoracic echocardiography (Acuson 128, 7.0-MHz Acuson V7 probe; Siemens, Malvern, Pa) from a right parasternal approach $(n=20)$. SF was determined independently by 2 different observers (A.R.K., M.S.C.) and calculated as follows:

$S F(\%)=($ End-diastolic dimension

- End-systolic dimension)/End-diastolic dimension.
Interobserver variability was $2.9 \% \pm 0.04 \%(P=.16)$ for SF. After administration of intravenous cefazolin $(20 \mathrm{mg} / \mathrm{kg})$ and heparin $(100 \mathrm{U} / \mathrm{kg})$, the left pleural cavity was entered anterolaterally through a fourth intercostal incision. A sample of blood was taken from the left atrium for blood gas and hematocrit analysis, and ventilation was adjusted to achieve standard parameters $\left(\mathrm{PaCO}_{2}, 45 \mathrm{~mm} \mathrm{Hg} ; \mathrm{PaO}_{2},>85 \mathrm{~mm} \mathrm{Hg}\right.$; fraction of inspired oxygen, $40 \%$ ). Sham-treated animals underwent thoracotomy only. In the hypoxemic group a left pulmonary arteryto-left atrium anastomosis was created by using a 5-mm, thinwalled polytetrafluoroethylene tube (Gore-Tex; W. L. Gore \& Associates, Inc, Flagstaff, Ariz). Postoperatively, the piglets were extubated when awake, and analgesia was achieved with transdermal fentanyl $(25 \mu \mathrm{g} / \mathrm{h}$ for 72 hours $)$. None of the animals were transfused with blood. On day 14, all animals were endotracheally intubated after induction with ketamine (30 $\mathrm{mg} / \mathrm{kg})$ and acepromazine $(1.2 \mathrm{mg} / \mathrm{kg})$ and ventilated to standard parameters after achievement of general anesthesia with isoflurane $1.5 \%$ and $40 \%$ fraction of inspired oxygen. Left ventricular SF was again measured by using transthoracic echocardiography. A blood sample was obtained from the descending aorta for arterial blood gas analysis and hematocrit measurement.

The animals were then killed with intravenous pentobarbital $(150 \mathrm{mg} / \mathrm{kg})$. Cardiac ventricles were harvested and immediately placed in phosphate-buffered saline at $-70^{\circ} \mathrm{C}$.

\section{Northern Blot Hybridization of $\mathrm{CcOx}$ Subunit I}

Total RNA was extracted from cardiac tissue by using the method of Chomczynski and Sacchi. ${ }^{8}$ As previously described, ${ }^{9-12} 10 \mu \mathrm{g}$ of denatured RNA was resolved by means of electrophoresis on $1.5 \%$ formaldehyde-containing agarose gels. Gels were transferred to nylon membrane and hybridized against purified, doublestranded phosphorous 32-labeled, CcOx subunit I cDNA probes (graciously provided by Dr Narayan G. Avadhani, University of Pennsylvania School of Veterinarian Medicine, Philadelphia, Pa). Autoradiography and densitometry were performed, and data were normalized to the density of the $18 \mathrm{~S}$ ribosomal subunit.

\section{Mitochondrial Isolation}

As previously described, cardiac ventricles were homogenized in $\mathrm{H}$ medium $(70 \mathrm{mmol} / \mathrm{L}$ sucrose, $220 \mathrm{mmol} / \mathrm{L}$ mannitol, 2.5 $\mathrm{mmol} / \mathrm{L}$ Hepes [pH 7.4], and $2 \mathrm{mmol} / \mathrm{L}$ ethylenediamine tetraacetic acid). ${ }^{12}$ Mitochondria were isolated by means of differential centrifugation, and mitochondrial protein concentration was determined by using the method of Lowry. ${ }^{12,13}$

\section{Protein Immunoblotting}

Samples $(10 \mu \mathrm{g})$ of mitochondrial protein were subjected to sodium dodecylsulfate-acrylamide gel electrophoresis and immunoblotting, as previously described. ${ }^{10,12}$ Blots were labeled with a primary polyclonal antibody to mouse $\mathrm{CcOx}$ subunit I (Molecular Probes, Eugene, Ore) and secondarily exposed to rabbit antimouse IgG (Santa Cruz Biotechnology Inc, Santa Cruz, Calif). The signal was detected with enhanced chemiluminescence (Amersham Pharmacia Biotech, Piscataway, NJ), and density was measured by means of scanning densitometry. 


\section{CcOx Steady-State Kinetics}

CcOx kinetics were assayed by using the method of Smith, in which the rate of oxidation of ferrocytochrome $\mathrm{c}$ was measured by following the decrease in absorbance at $550 \mathrm{~nm} \cdot{ }^{12,13}$ Assays were executed in a $1-\mathrm{mL}$ reaction volume containing $50 \mathrm{mmol} / \mathrm{L} \mathrm{PO}_{4}{ }^{-2}$ (pH 7.0), 2\% lauryl maltoside, and $0.5 \mu \mathrm{g}$ of mitochondrial protein. Ferrocytochrome $\mathrm{c}$ was added at a concentration of 20 $\mathrm{mmol} / \mathrm{L}$ to initiate the reaction. First-order rate constants were calculated from mean values of 3 to 4 measurements. Specific activity was calculated by using $21.1 \mathrm{mM}^{-1} \cdot \mathrm{cm}^{-1}$ as the extinction coefficient of ferrocytochrome c at $550 \mathrm{~nm}$.

\section{Measurement of Heme a, $a_{3}$ Content}

Mitochondrial heme $a, a_{3}$ content was calculated from the difference in spectra (dithionate/ascorbate reduced minus ferricyanide oxidized) of mitochondria solubilized in $10 \%$ lauryl maltoside by using an absorption coefficient of $24 \mathrm{mM}^{-1} \cdot \mathrm{cm}^{-1}$ at 605 to 630 $\mathrm{nm}$, as described by Vijayasarathy and colleagues. ${ }^{12,13}$ Turnover number was calculated by dividing $\mathrm{CcOx}$-specific activity by the heme $a, a_{3}$ content. ${ }^{13}$

\section{Statistical Analysis}

Sixteen animals per group were evaluated. All animals had blood sampled for $\mathrm{PaO}_{2}$ and hematocrit values. Echocardiographic determination of SF was performed in 20 piglets (10 in each group). Cardiac ventricles from 12 piglets were used for mRNA and protein evaluation, whereas ventricular mitochondria from 20 piglets were used for kinetic assays and heme determination. Data are presented as the means \pm standard deviation. Statistical significance was assessed by using the Student $t$ test.

\section{Results}

$\mathrm{PaO}_{2}$ and Hematocrit

Baseline $\mathrm{PaO}_{2}$ and hematocrit values were similar between the groups (Figure 1). Two weeks after the procedure, hypoxemic piglets had significantly lower $\mathrm{PaO}_{2}(38 \pm 10$ $\mathrm{mm} \mathrm{Hg}, P<.001)$ and higher hematocrit values $(31.4 \% \pm$ $2.9 \%, P<.001)$ compared with sham-operated animals $\left(\mathrm{PaO}_{2}, 140 \pm 46.7 \mathrm{~mm} \mathrm{Hg}\right.$; hematocrit value, $24.6 \% \pm$ $3.9 \%$; Figure 1).

\section{Left Ventricular SF}

Left ventricular SF was similar between hypoxemic piglets and sham-operated control animals. Baseline SF was 35\% $\pm 5 \%$ in the hypoxemic group and $36 \% \pm 6 \%$ in the sham-operated animals. Two weeks after the procedure, SF was $30 \% \pm 6 \%$ in hypoxemic piglets and $31 \% \pm 4 \%$ in sham-operated control animals. There was no significant difference between postprocedure SF and baseline SF within groups.

\section{Steady-State Levels of CcOx Subunit I mRNA}

Steady-state levels of total ventricular CcOx I mRNA were significantly increased by 1.6 -fold in hypoxemic piglets versus sham-operated animals $(P<.04$, Figure 2$)$. Right ventricular $\mathrm{CcOx}$ I mRNA levels were significantly in-
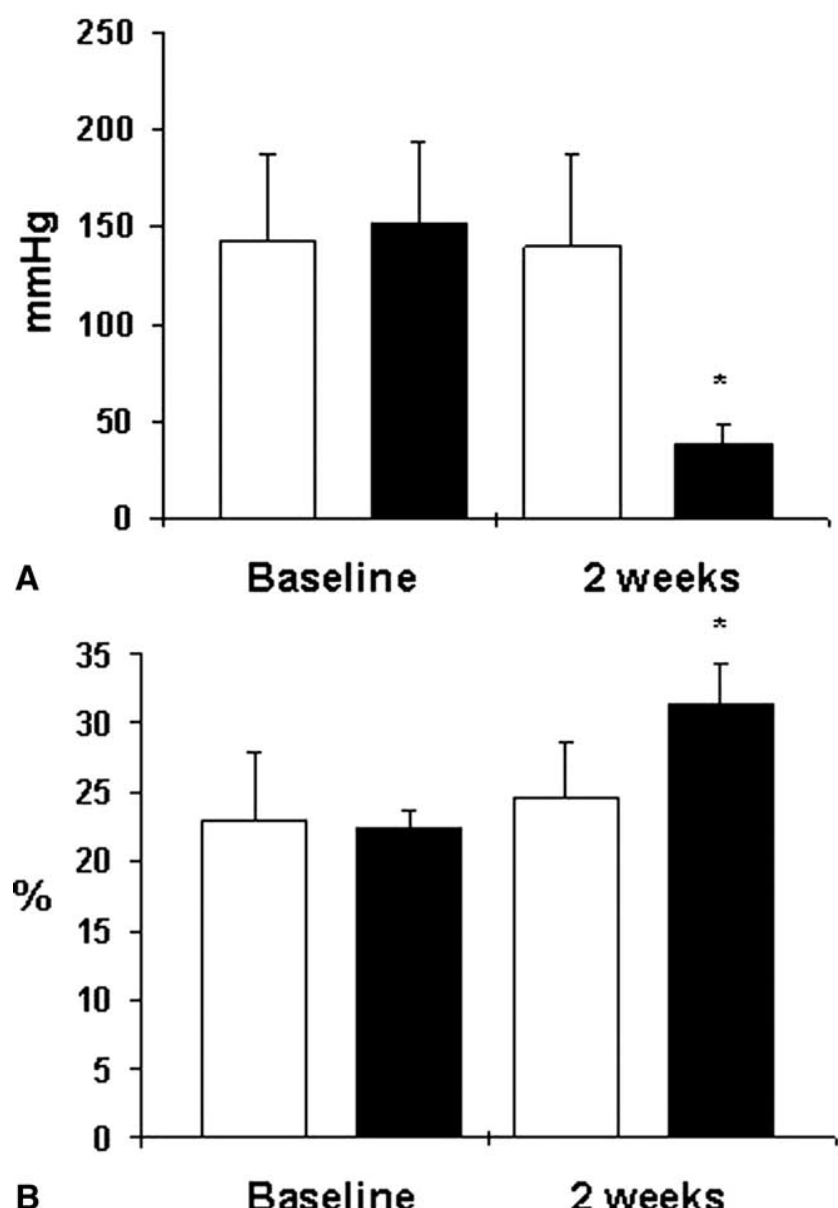

Figure 1. Changes in partial pressure of arterial oxygen and hematocrit values during cyanosis. A, Partial pressure of arterial oxygen at baseline and 2 weeks after the procedure for the sham-operated control (open bars) and hypoxemic (filled bars) groups are represented. Values are expressed as the mean \pm standard deviation in millimeters of mercury. B, Hematocrit values at baseline and 2 weeks after the procedure for the shamoperated (open bars) and hypoxemic (filled bars) groups are represented. Values are expressed as the mean \pm standard deviation in percentage. $N=16$ per group. ${ }^{*} P<.001$.

creased by 1.7 -fold in the hypoxemic group, whereas left ventricular levels were increased by 1.6-fold compared with those in control animals $(P<.05$, Figure 2$)$. There was no statistical difference between right and left ventricular levels within groups.

\section{Steady-State Levels of CcOx Subunit I Protein}

Steady-state levels of total ventricular $\mathrm{CcOx}$ I protein were significantly increased by 1.5 -fold in hypoxemic piglets versus control animals $(P<.01$, Figure 3$)$. Right and left ventricular $\mathrm{CcOx}$ I protein levels were significantly increased in hypoxemic animals by 1.4- and 1.5 -fold, respec- 


\section{Sham Hypoxemic}

\section{$\mathrm{CcOx} I$}

$18 S$
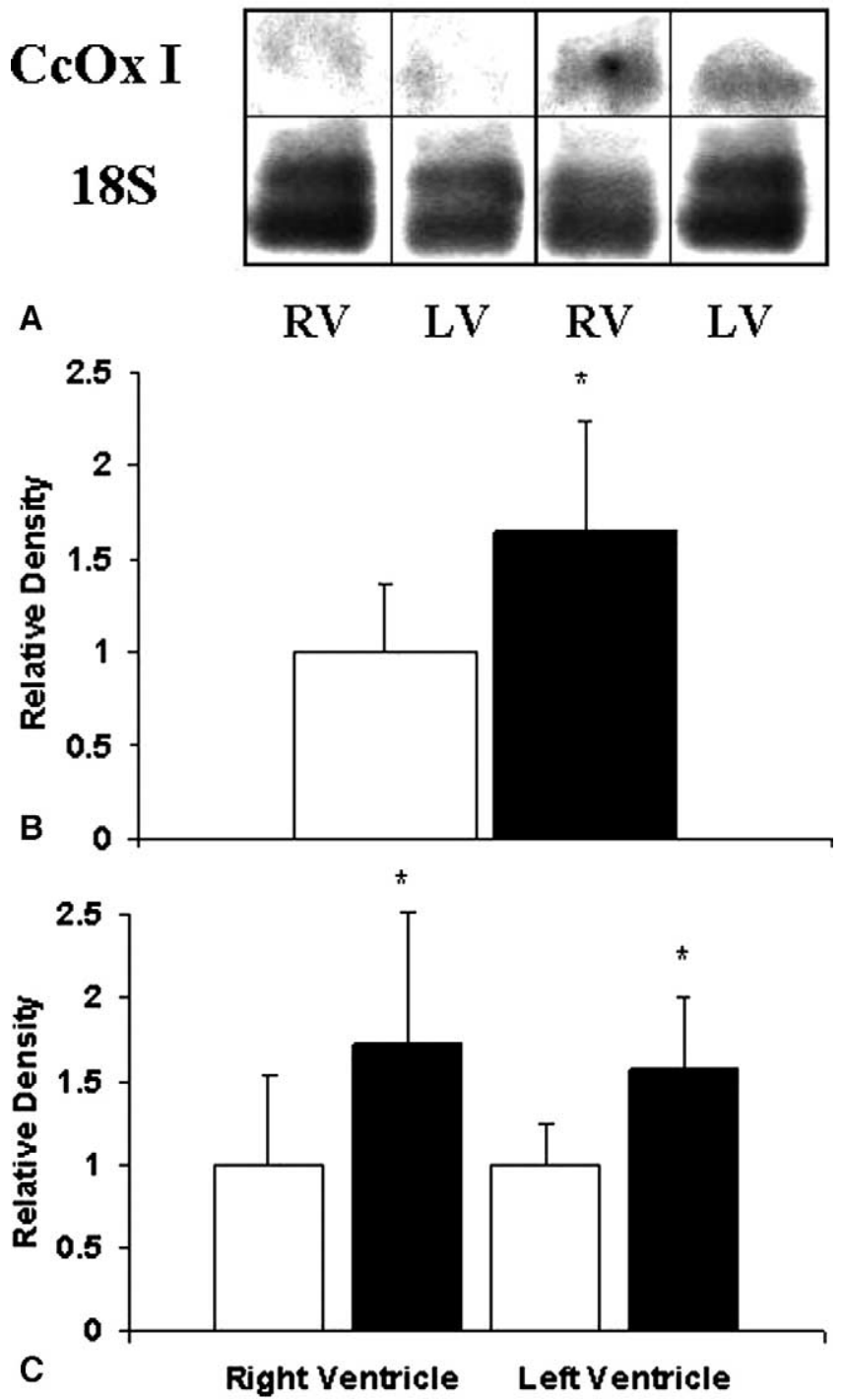

Figure 2. Steady-state levels of ventricular cytochrome oxidase subunit I (CcOx I) mRNA. A, A representative Northern blot is depicted. Cytochrome oxidase subunit I mRNA from the right ventricle (RV) and left ventricle (LV) of both the hypoxemic and sham-operated groups are shown. Densities were determined and normalized to the $\mathbf{1 8 S}$ ribosomal subunit. B, Total cytochrome oxidase subunit I mRNA levels for the sham-operated (open bars) and hypoxemic (filled bars) groups are represented. C, Right and left ventricular cytochrome oxidase subunit I mRNA levels are shown for the sham-operated (open bars) and hypoxemic (filled bars) groups. Sham-operated control values were arbitrarily set to equal a relative density of 1 . All values are expressed as the mean \pm standard deviation. $N=6$ per group. ${ }^{*} P<.05$.

\section{CcOx I}

A

Sham Hypoxemic
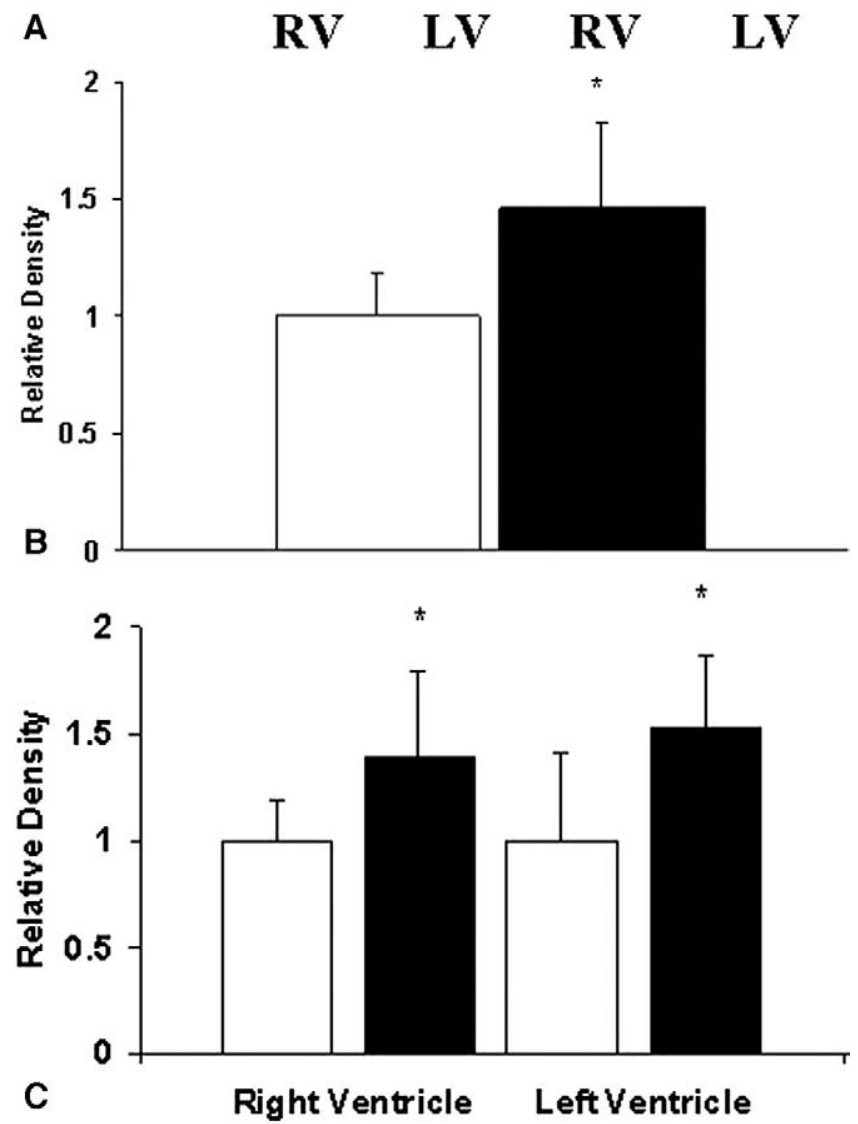

Figure 3. Steady-state levels of ventricular cytochrome oxidase subunit I ( $\mathrm{CcOx}$ I) protein. A, A representative Western blot is depicted. Cytochrome oxidase subunit I protein from right ventricular (RV) and left ventricular (LV) mitochondria of both the sham-operated and hypoxemic groups are shown. B, Total cytochrome oxidase subunit I protein levels for sham-operated (open bars) and hypoxemic (filled bars) groups are represented. C, Right and left ventricular cytochrome oxidase subunit I protein levels are shown for the sham-operated (open bars) and hypoxemic (filled bars) groups. Sham-operated control values were arbitrarily set to equal a relative density of 1 . All values are expressed as the mean \pm standard deviation. $N=6$ per group. ${ }^{*} P$ $<.05$.

tively ( $P<.05$, Figure 3 ). As with mRNA levels, there was no difference between right and left ventricular protein levels within groups.

CcOx Activity and Heme a, $\mathbf{a}_{3}$ Content

Chronic hypoxemia significantly increased $\mathrm{CcOx}$ kinetic activity by 2.5 -fold (Figure $4, A$ ). In hypoxemic piglets 
A

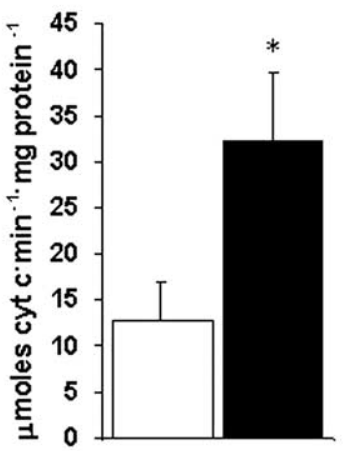

B

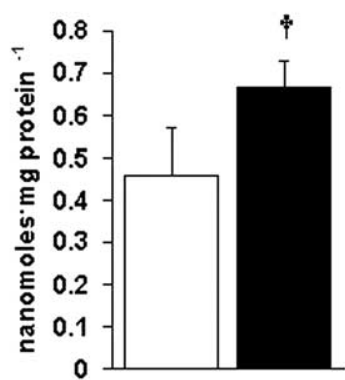

C

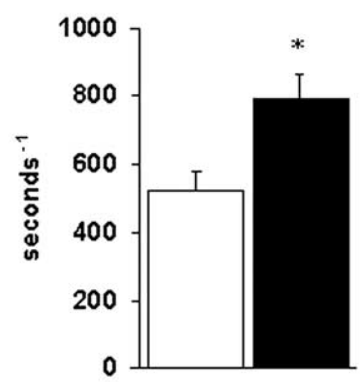

Figure 4. Steady-state cytochrome oxidase kinetic activity. A, Specific activity of ventricular cytochrome oxidase after the addition of $20 \mathrm{mmol} / \mathrm{L}$ ferrocytochrome c (cyt c). The open bar represents activity for the sham-operated control group, and the filled bar represents the hypoxemic group. Values are expressed as the mean \pm standard deviation in micromoles of cytochrome c per minute per milligram of mitochondrial protein. $B$, Heme $a_{1} a_{3}$ content of ventricular myocytes from the sham-operated control (open bar) and hypoxemic (filled bar) groups are represented. Values are expressed as the mean \pm standard deviation in nanomoles per milligram of mitochondrial protein. C, Turnover number for the sham-operated control (open bar) and hypoxemic (filled bar) groups are represented. Values are expressed as the mean \pm standard deviation per second. $N=10$ per group. ${ }^{*} P<.01,+P<.05$.

CcOx-specific activity was $32.2 \pm 7.5 \mu$ moles of cytochrome $\mathrm{c} \cdot \mathrm{min}^{-1} \cdot \mathrm{mg}^{-1}$ of protein, whereas in shamoperated control animals $\mathrm{CcOx}$ activity was $12.9 \pm 4.0$ $\mu$ moles of cytochrome $\mathrm{c} \cdot \mathrm{min}^{-1} \cdot \mathrm{mg}^{-1}$ of protein $(P<$ $.01)$. Measurement of heme $a, a_{3}$ content, the binuclear center of the $\mathrm{CcOx}$ active site, revealed a 1.5 -fold increase in chronic hypoxemic piglets $(P<.05$; Figure $4, B)$. This paralleled changes seen in $\mathrm{CcOx}$ subunit I protein levels. The turnover number of $\mathrm{CcOx}$ represents moles of substrate converted to product per unit time. ${ }^{14}$ The turnover number increased by 1.5 - fold in hypoxemic piglets versus shamoperated animals $(P<.01$; (Figure $4, C)$.

\section{Discussion}

Many investigators have postulated that cellular adaptive mechanisms exist during cyanosis, preserving cardiac function and minimizing hypoxic injury. ${ }^{5}$ Upregulation of $\mathrm{CcOx}$ in the setting of chronically decreased tissue oxygen tension might be one such mechanism. To test this hypothesis, we used a newborn piglet model of chronic hypoxemia caused by the creation of a left pulmonary artery-to-left atrium shunt. Several different models of chronic hypoxemia have been used experimentally. ${ }^{7}$ This specific model, however, is a well-accepted model of chronic hypoxemia. It is advantageous to other models of chronic hypoxemia because right ventricular pressure and volume states are not altered, and cardiac index is maintained. ${ }^{7}$ Here we report that left ventricular $\mathrm{SF}$ is unaltered during chronic hypoxemia. Importantly, this supports the description of maintained preischemic cardiac performance in the cyanotic heart. ${ }^{2-4}$ In the present study creation of a left pulmonary artery-to-left atrium shunt resulted in a significant decrease in $\mathrm{PaO}_{2}$ from $151 \pm 43 \mathrm{~mm} \mathrm{Hg}$ to $38 \pm 10 \mathrm{~mm} \mathrm{Hg}$. As a result of this decrease in oxygen content, the hematocrit value increased from $22 \% \pm 1.3 \%$ to $31 \% \pm 2.9 \%$. These alterations in the hypoxemic piglets mimic findings seen in children with cyanotic congenital heart disease.

Ventricular myocardium demonstrated significantly increased steady-state levels of $\mathrm{CcOx}$ subunit I mRNA, protein, and kinetic activity in hypoxemic animals. Not surprisingly, increases in myocardial heme a, $\mathrm{a}_{3}$ content paralleled changes in $\mathrm{CcOx}$ protein. Increased $\mathrm{CcOx}$ activity caused solely by increased heme content would result in enzyme turnover close to baseline. In hypoxemic animals, however, turnover number increased by 1.5 -fold. This indicates that the observed increase in $\mathrm{CcOx}$ activity during chronic hypoxemia was not only due to an increase in enzyme content but also to an increase in the enzyme's ability to convert substrate to product. This adaptive response has been previously described in hypoxic cells. ${ }^{15}$ Such increases in enzyme expression and activity could lead to preserved cellular bioenergetics and myocardial ATP levels. Thus oxidative phosphorylation in chronically hypoxemic myocardium is probably maintained in the setting of decreased oxygen tension by increased myocardial $\mathrm{CcOx}$ content and activity. Subsequently, preserved aerobic capacity in hypoxemic myocardium probably maintains cardiac performance. Therefore upregulation of myocardial $\mathrm{CcOx}$ might be an adaptive mechanism during hypoxemia, preserving cellular bioenergetics and cardiac function. 
These changes in $\mathrm{CcOx}$ gene expression and activity might have important implications for patients with congenital cyanotic heart disease. Children with preoperative cyanosis are known to have higher morbidity and mortality compared with acyanotic patients. ${ }^{1}$ Reactive oxygen species are generated during ischemia and reperfusion and are known to impair $\mathrm{CcOx}$ activity. ${ }^{16}$ Because cardiomyocytes might depend on increased $\mathrm{CcOx}$ activity to maintain normal function in the cyanotic heart, reactive oxygen speciesinduced inhibition of $\mathrm{CcOx}$ could lead to a significant defect in oxidative phosphorylation and might dramatically depress postischemic cardiac function.

\section{Limitations}

This model of chronic hypoxemia attempts to mimic the human condition of cyanosis caused by congenital heart disease. Surgical creation of a shunt in the postnatal period is an obvious limitation. A second limitation is that we assume that increased $\mathrm{CcOx}$ expression preserves ATP levels in hypoxemic myocardium. Although other investigators have demonstrated that ATP levels are unchanged in the cyanotic heart relative to acyanotic levels, we have not made such measurements. It can be argued that measurement of ATP levels reveals nothing about the integrity of oxidative phosphorylation. This is because myocardium can downregulate oxygen consumption, energy requirements, and ATP demand. ${ }^{17}$ Cardiomyocytes maintain viability and preserve ATP levels during hypoxia. ${ }^{17}$ Therefore eliciting changes in cellular bioenergetic capacity might be better accomplished by examining individual electron transport enzyme gene expression and activity, as we have done. Finally, echocardiographic determination of cardiac performance is limited. This technique is preload dependent and does not truly assess myocardial contractility and elastance. However, we used echocardiographic assessment of cardiac performance to noninvasively repeat measurements in the animals over a 2-week period. This allowed us to use each piglet as its own control animal to assess differences within and between groups.

\section{Summary}

Here we demonstrate significant increases in CcOx mRNA, protein, and kinetic activity in the chronically hypoxemic heart. Such changes might be adaptive, preserving cardiomyocyte function during hypoxemia. These alterations could have important implications for patients with congenital cyanotic heart disease.

\section{References}

1. Merante F, Mickle DA, Weisel RD, Li RK, Tumiati LC, Rao V, et al. Myocardial aerobic metabolism is impaired in a cell culture model of cyanotic heart disease. Am J Physiol. 1998;275:H1673-81.

2. Najm HK, Wallen WJ, Belanger MP, Williams WG, Coles JG, Van Arsdell GS, et al. Does the degree of cyanosis affect myocardial adenosine triphosphate levels and function in children undergoing surgical procedures for congenital heart disease? J Thorac Cardiovasc Surg. 2000;119:515-24.

3. Corno AF, Milano G, Samaja M, Tozzi P, von Segesser LK. Chronic hypoxia: a model for cyanotic congenital heart defects. $J$ Thorac Cardiovasc Surg. 2002;124:105-12.

4. Lupinetti FM, Wareing TH, Huddleston CB, Collins JC, Boucek RJ Jr, Bender HW Jr, et al. Pathophysiology of chronic cyanosis in a canine model. Functional and metabolic response to global ischemia. $J$ Thorac Cardiovasc Surg. 1985;90:291-6.

5. Bitar FF, el Sabban M, Bitar H, Diab K, Mroueh S, Nasser M, et al. Lack of apoptosis in the hypoxic brain of a rat model mimicking cyanotic heart disease. Brain Inj. 2002;16:891-900.

6. Dernevik L, Bylund-Fellenius AC, Ekroth R, Holm J, Idstrom JP, Schersten T. Enzymatic activities in heart and skeletal muscle of children with cyanotic and noncyanotic congenital heart disease. Thorac Cardiovasc Surg. 1988;36:310-2.

7. Nagashima M, Nollert G, Stock U, Sperling J, Hatsuoka S, Shum-Tim $\mathrm{D}$, et al. Cardiac performance after deep hypothermic circulatory arrest in chronically cyanotic neonatal lambs. J Thorac Cardiovasc Surg. 2000;120:238-46.

8. Chomczynski P, Sacchi N. Single-step method of RNA isolation by acid guanidinium thiocyanate-phenol-chloroform extraction. Anal Biochem. 1987;162:156-9.

9. Deutschman CS, Andrejko KM, Haber BA, Bellin L, Elenko E, Harrison R, et al. Sepsis-induced depression of rat glucose-6phosphatase gene expression and activity. Am J Physiol. 1997;273: R1709-18.

10. Weiss YG, Bouwman A, Gehan B, Schears G, Raj N, Deutschman CS. Cecal ligation and double puncture impairs heat shock protein 70 (HSP-70) expression in the lungs of rats. Shock. 2000;13:19-23.

11. Andrejko KM, Deutschman CS. Altered hepatic gene expression in fecal peritonitis: changes in transcription of gluconeogenic, beta-oxidative, and ureagenic genes. Shock. 1997;7:164-9.

12. Levy RJ, Vijayasarathy C, Raj NR, Avadhani NG, Deutschman CS. Competitive and noncompetitive inhibition of myocardial cytochrome C oxidase in sepsis. Shock. 2004;21:110-4.

13. Vijayasarathy C, Biunno I, Lenka N, Yang M, Basu A, Hall IP, et al. Variations in the subunit content and catalytic activity of the cytochrome $\mathrm{c}$ oxidase complex from different tissues and different cardiac compartments. Biochim Biophys Acta. 1998;1371:71-82.

14. Stryer L. Introduction to enzymes. In: Stryer L. editor. Biochemistry. 3rd ed. New York: Freeman; 1988. p. 177-200.

15. Vijayasarathy C, Damle S, Prabu SK, Otto CM, Avadhani NG. Adaptive changes in the expression of nuclear and mitochondrial encoded subunits of cytochrome c oxidase and the catalytic activity during hypoxia. Eur J Biochem. 2003;270:871-9.

16. Lesnefsky EJ, Slabe TJ, Stoll MS, Minkler PE, Hoppel CL. Myocardial ischemia selectively depletes cardiolipin in rabbit heart subsarcolemmal mitochondria. Am J Physiol. 2001;280:H2770-8.

17. Budinger GR, Duranteau J, Chandel NS, Schumacker PT. Hibernation during hypoxia in cardiomyocytes. Role of mitochondria as the $\mathrm{O} 2$ sensor. J Biol Chem. 1998;273:3320-6. 